\title{
Thinking on the industrial development of the cotton planting and production in Xinjiang
}

\author{
Fan Rong, Ma Qiong \\ College of Economic and Management, Tarim University, Alar, Xinjiang 843300
}

Key words: Xinjiang, cotton industry, development countermeasures

\begin{abstract}
Xinjiang, as the cotton production place in our country, occupies over half of the total cotton output in our country with its annual output, but in recent years, its output has been increasing while the economic benefit has been in a low level owing to the constant fluctuation in cotton price and unstable planting scale, which is ultimately because the cotton planting, processing and sales links in Xinjiang are disperse without forming synergistic effect. Therefore, the author analyzes the cotton production advantages and problems in Xinjiang, puts forward to take the largescale cotton spinning industry as the lead, form the interests community through equity relationship and contract with the cotton companies, unginned cotton processing enterprises and cotton planters, and hopes to promote the rapid and stable development of the cotton industry in Xinjiang by the means of establishing the new type cotton industrial chain.
\end{abstract}

\section{Introduction}

Owing to its congenital advantages such as the rich sunlight-heat resources, Xinjiang is suitable to plant and produce cottons, moreover, the cotton output in Xinjiang is always staying in a higher level. But in recent years, some problems have appeared in the cotton industry of Xinjiang, on the one hand, the market price fluctuation causes the fluctuation of the planting scale, the two phenomenons of difficulty in purchasing cotton and selling cotton occur alternately, and the cotton in Xinjiang exists with the coexistence situation of cotton shortage and excess within certain period; on the other hand, the cotton planting structure is unreasonable and the cotton varieties are mixed, which affect the cotton brand and quality of Xinjiang, and weaken its competitive advantage; in addition, the disperse cotton processing mode causes the declining in the raw cotton quality and much waste in resources. Nowadays, under the background of economic globalization, if the cotton industry in Xinjiang has no innovative development idea, it will be difficult to retain the sustainable and healthy development in the industry.

\section{Analysis on the current problems existed in the cotton industry of Xinjiang}

The cotton price in Xinjiang was relatively stable before the year of 2000, while the cotton price in Xinjiang has presented a large fluctuation since the cotton floated freely in 2000, which is because the cotton market mechanism is in the preliminary stage and the international market has large impact on it. The large fluctuation in the cotton price has affected the healthy development of the cotton industry in Xinjiang. Besides, the cotton variety is various and mixed, and its processing quality is unstable. With the development of social economy, more and more processing enterprises have begun to engage in cotton processing, the processing capability of thousands of processing enterprises in Xinjiang has surpassed more than two times of the total cotton output in Xinjiang. However, the current processing enterprises are featured of small production scale, backward management level and serious improvidence, besides, they exist with the problems such as raising the price for scare buying in case of resource shortage and mixed-level acquisition, which cause the poor processing quality, large fluctuation in market price and quality mix. In addition, the cotton acquisition price is not increased with the increasing of the cotton planting cost owing to the declining in the cotton quality and variety, and the cotton planters have no increasing in the benefits 
but in the output, therefore, some cotton planters gradually give up producing cotton but transfer to plant the commercial crops with higher additional value, such as tomato, grape and apple. Owing to the unstable market sales situation, the cotton enterprises should undertake the risks of cotton regrating cost and price declining under the poor situation in consumption; while they have no cottons for purchasing and selling under the good situation in market. The author thinks the reason for the above problems is that the cotton planting, processing and sales links are disperse without forming effective integrated industrial chain thus to cause the links form no mechanism of risk and benefit sharing. Therefore, it needs to establish an innovative mode to integrate the upstream and downstream relationship of the original industrial chain, clarify the risk price system thus to promote the healthy development of the cotton industry of Xinjiang.

\section{Countermeasures and suggestions on the industrial development of the cotton planting and production in Xinjiang}

Establish perfect cotton production and processing standard system, including a set of rules and standards on seed cultivation, planting and picking, acquisition and processing, storage and transport. Conduct control from the source of planting, cultivate the high quality cotton seeds in a certain orientation in accordance with the different natural situations for cotton planting, strengthen the good seed promotion and growth and realize the unified seed supply and one land for one variety thus to prevent the mix and degradation of cotton seeds. Meanwhile, strictly control the three links of picking, acquiring and processing, and strenghen the inspection and test on the cotton quality. Wherein, it is needed to pick, store, bask and sell the cottons respectively thus to avoid level mix in the picking link, forbid the interfusion of foreign fibers in the acquisition and processing links, conduct processing strictly in accordance with the national cotton standards thus to enhance the cotton quality.

Xinjiang has a vast territory while the sunlight-heat, water and land resources are largely different in different regions, therefore, it is needed to start from optimizing the cotton variety structure, conduct cotton production in accordance with the requirements on the cotton variety and quantity, thus to gradually realize the scientific layout, professionalized production and standard quality, and promote the transformation of cotton production in Xinjiang from quantity increasing to quality benefit.

Strengthen the cooperation with the scientific research units, besides, the new cotton industry group has unified guidance and provides certain expenses for the scientific research units thus to accelerate the promotion and transformation of the new cotton variety and scientific achievements, enhance the cotton production output and quality and promote the cotton planters to improve the production efficiency and the enterprises to increase profits.

For the cotton industry group, how to avoid the risks from the market price fluctuation plays an important significance in its commercial operation. The cotton industry group gives the orders to the cotton planters on a basis of minimum protection price, meanwhile, escapes from the adverse influence through hedging, locking in profits and risks as well as transferring the price change in the futures market, which will be helpful to solve the problem of low performance rate in contract farming and really form the benefit and risk sharing mechanism with the cotton planters and guarantee the output and profit increasing of cotton.

Firstly, give support to the infrastructure construction of cotton. The cotton production is the typical weak industry of high investment, high risk and low return, which invests a lot in the infrastructure with long period in capital return, wherein, large number of capitals are needed to be invested in the farmland transformation, water-saving irrigation, anti-seepage of channels and entironment. From the perspective of infrastructure investment, the local government should give proper financial support and comprehensively improve the infrastructures for cotton field thus to give full play of the cotton production capacity in Xinjiang.

Secondly, standardize the market order and strengthen the credit system construction. The related government department should strengthen supervision and guidance on the various contracts for cotton industry production, processing and sales links, and maintain the market order through 
certain administrative and judicial means. For the behaviors artificially destroying the cotton acquisition, processing and sales links, they should adopt the means of warning,criticizing, administrative penalty and judicial sanction to standardize the market credit construction and guarantee the effective operation of the cotton industry chain.

Strengthen the science and technology service capability and realize the "dual coordination" of ecological protection and industrial development. Breaking though the bottleneck of ecology in the cotton industry development is the key link for the sustainable development of the cotton windsurf. It is needed to take the science and technology service as the core work from the perspective of the real situation of the cotton industry development in Xinjiang. Firstly, strengthen the promotion degree of decompose film. The pollution from mulching film is one of the main ecological problems faced by the cotton planting in Xinjiang. In recent years, with the increasing pollution of the mulching film, the various-level departments in Xinjiang has strengthened the promotion degree of decompose film while the promotion effect is unsatisfactory owing to the expense and operation of decompose film. Therefore, it needs to consider the subsidy system for decompose film thus to reduce the usage cost of decompose film. Meanwhile, the related science and technology promotion department should strengthen the promotion in the decompose film usage technology, strive to modify the "reliance on technology" of the traditional mulching film thus to make the planters adapt to the operation skills of decompose film as soon as possible. Secondly, positively utilize the good seeds and proper cultivation technology. Rely on the national farming-benefit policy such as subsidy for good seed, largely promote and popularize the good seed; connect with the professional scientific research institutes closely, positively strive for the national-level and region-level scientific research funds and continue to carry out the work of good seed cultivation and updating; promote the technologies such as drip irrigation under plastic film, high density cultivation, intercropping, crop rotation, soil testing and fertilizer recommendation, try to maintain the ecological balance of soil.

Establish the new type cotton industry chain, namely, take one certain large-scale production industry chain enterprise as the lead,take capitals as bond, by the methods of equity cooperation, rental, entrusted processing, form the new cotton industry group by the cotton spinning enterprise, cotton company and unginned cotton enterprise, thus to implement the strategy of large group company driving the industrial development; besides, take the market as orientation, develop the contract farming and form the interests community through the contracts thus to integrate the cotton planting, processing and marketing links, guarantee the interests of all links in the cotton industry chain and make the cotton industry in Xinjiang really step onto the development route of group,large scale and intensification.

Firstly, establish new shareholding cotton operation company. The cotton spinning enterprise and the cotton company jointly establish the new cotton operation company by the means of equity cooperation and perfect the corporate governance structure in accordance with the modern enterprise system. From the perspective of capital structure, one party can hold the share relatively or absolutely. From the perspective of member arrangement in the board of directors, the minority shareholder should have full right of voting thus to avoid the phenomenon of the single-large shareholder or damages on the interests of minority shareholder.

The new cotton operation company forms the interests community together with the ginneries by the means of partial shareholding, partial rental and partial entrusted processing thus to form a new cotton industry group involving the processing, sales and terminals.

Secondly, establish the commercial operation mode of the cotton industry group. From the perspective of cotton planting, the cotton industry group cooperates with the cotton planters for long time thus to develop the contract farming in accordance with its own demands and the market requirements in domestic and overseas, as well as combined with the local situation of natural resources; besides, it provides the diversified fund support, agricultural capital service and technology service in accordance with the stipulations in the contract by the means of unified seed and unified planting technology. In order to reduce the planting risks of the cotton planters and enhance their enthusiasm in cotton planting, the cotton industry group will determine the minimum 
safeguard price and acquire the cotton seeds in unified way. For the premium to market, the company will conduct second sharing with the cotton planter according to certain proportion. For the processing link, the cotton operation company will determine the settlement and payment of the related expenses such as processing fee and rental fee together with the ginneries by the means of contract. In order to stabilize the market and avoid the cutthroat competition, the ginneries can not sell ginned cottons privately, which should be sold by the new cotton company in unified way, besides, the settlement price should base on the local market price index in case of delivery. In addition, the risk in market price fluctuation of cotton and in sales should be independently born by the cotton company while the cotton company avoids the adverse influence from price fluctuation relying on its professional market experience and futures market. In order to maintain the normal operation, the cotton company should charge the management fee of certain proportion according to the sales volume. Based on this mode, the cotton planter, cotton company and ginnery will give full play to their own professional advantages and guarantee their planting scale, sales scale and sales price respectively thus to restrain the risk from market fluctuation.

\section{Conclusion}

Firstly, we must affirm that the achievements of the cotton industry in Xinjiang in the previous year are unblamable, meanwhile, we must also recognize that the cotton industry development in Xinjiang still faces many problems which restrict the further development of the cotton industry in Xinjiang. With the confirming on the new normal of the economic development in our country, Xinjiang has faced larger difficulty in realizing the goal of all-round well-being. The cotton industry, as the important industry to optimize the economic structure in Xinjiang and realize the all-round well-being, should continue to innovation and persist in sustainable development based on the recognition on the situation, optimizes the cotton planting structure through perfecting the cotton production standard system, pays attention to the cotton price avoidance, enlarges the policy support of the government on cotton and establish the new type cotton production industry chain thus to accelerate the rapid and stable development of the cotton production industry in Xinjiang.

\section{Reference documentation:}

[1] Ma Aiqin. Thinking on the sustainable development of the cotton industry in Xinjiang[J]. China Fiber Inspection,2015(09): 46-47.

[2] Hali Danmu·Abra. Countermeasures on the cotton industry development in Xinjiang [J]. Times Agricultural Machinery,2015(01): 160-162.

[3] Han Gen. Current situation of the cotton industry development in Xinjiang and the idea of sustainable development[J]. Anhui Agricultural Sciences, 2012（14） : 8343-8244.

[4] Duan Li. Strategic thinking on the cotton industry development in Xinjiang [J]. Social sciences in Xinjiang,2011(01): 43-45. 